\title{
Prediction of Tool Fracture in Punching of Thick Steel Plate
}

\author{
Minoru Yamashita, ${ }^{1 *}$ Taiki Murase, ${ }^{2}$ and Makoto Nikawa ${ }^{1}$ \\ ${ }^{1}$ Department of Mechanical Engineering, Gifu University, 1-1 Yanagido, Gifu City, Gifu 501-1193, Japan \\ ${ }^{2}$ Graduate School of Natural Science and Technology, Gifu University, \\ 1-1 Yanagido, Gifu City, Gifu 501-1193, Japan
}

(Received May 14, 2020; accepted August 28, 2020)

Keywords: acoustic emission, punching, tool fracture, prediction

The sensing of acoustic emission (AE) is efficiently used for the detection of the crack initiation of brittle materials and defects in plastic forming and other manufacturing processes. We carried out circular hole punching tests using carbon steel S45C plates of 5 or $6 \mathrm{~mm}$ thickness. The objective was to capture the occurrence of cracks as a predictive phenomenon of punch fracture and their propagation during punching by using an AE sensor. The impulsive stress acting on the punch due to the sudden drop in punch force at the fracture of the plate was also measured using strain gages. This stress induced fracture at the stepped portion of the punch. The maximum tensile stress of the punch depended on the fillet radius at the stepped portion. A reciprocal punching test using both plates alternately was performed to evaluate the detection of crack initiation using an AE waveform. Features in the AE waveform due to crack initiation and the frictional behavior of the crack were captured.

\section{Introduction}

Methods of sensing physical quantities such as force, displacement, strain, and stress in manufacturing tools, machines, and materials have been investigated. Strain gages, piezoelectric transducers, and acoustic emission (AE) and fiber optic sensors are commonly used. There is an increasing requirement for technology to predict the occurrence of defective products by using sensors that deliver insights in real time. Internet of Things (IoT) and AI systems may support production flow monitoring in connected factories and adjust process parameters to continue production. The sensed data and the system also enable the predictive maintenance of tools and machines.

In plastic forming, AE monitoring has been carried out in sheet metal forming. ${ }^{(1)}$ A friction source detection system using multiple AE sensors was proposed for the deep drawing of sheet metal. ${ }^{(2)}$ An online forging support system based on AE analysis was also proposed. ${ }^{(3)}$ The micromechanical behavior and fracture mechanisms of high-strength steels for automotive components were studied. ${ }^{(4)}$ A method of predicting the quality of hot-rolled strips using an AE signal was proposed. ${ }^{(5)}$ The frictional condition of the curved part of a die was monitored during bending under tension. ${ }^{(6)}$ The onset of galling in strip reduction was investigated. ${ }^{(7)} \mathrm{A}$ *Corresponding author: e-mail: minoruy@gifu-u.ac.jp https://doi.org/10.18494/SAM.2020.2943 
technique for process monitoring in the deep drawing of a steel sheet was presented. ${ }^{(8)}$ Smart metal forming with a digital process and IoT was reviewed. ${ }^{(9)}$ In-process sensors for measuring the material deformation in a die cavity were discussed for deep drawing and tube hydroforming processes. ${ }^{(10)}$ Various sensing technologies used to visualize the phenomena in plastic forming were reviewed. ${ }^{(11)}$ However, there is no research on the crack behavior in forming tools, because experimental conditions are difficult to achieve in the laboratory.

The stress signal from a press column surface in punching processes was monitored and an effective method for health condition monitoring was presented. ${ }^{(12)}$ Wrinkles in sheet metal forming were evaluated from their ultrasonic reflection characteristics. ${ }^{(13)}$ The measurement of demolding resistance in polymer injection molding was also measured using a newly developed measurement unit installed in the mold. ${ }^{(14)}$ However, there has been almost no research on the forecasting tool fracture.

Sensing the crack initiation of brittle materials has also been examined. The total AE count was found useful for sensing crack initiation in nonhomogeneous rocks. ${ }^{(15)}$ A fiber optic sensor has been shown to be useful for monitoring cracks in concrete. ${ }^{(16)}$ The sensing of failure or crack growth has been attempted for various fatigue or repetitive loading situations. The damage of woven composites under compression after multiple impacts has been assessed. ${ }^{(17)}$ Fatigue microcracks have also been investigated. ${ }^{(18)}$ The potential for AE sources to be used for incipient damage detection in the case of rolling contact fatigue has been evaluated. ${ }^{(19)}$ It has been pointed out that caution is required when using a number of test pieces, such as in a fatigue test, because it is known that slight differences in experimental conditions, such as the clamping force of the material, affect the detected AE waveform.

Crack growth in welding joints of mooring chains was monitored by stress pulse propagation that was numerically analyzed to evaluate structural health. ${ }^{(20)}$ Hydrogen-induced cracking in high-strength steel welded joints was evaluated. A crack initiation criterion was derived using $\mathrm{AE}$ and the finite element method. ${ }^{(21)}$ Understanding the stress behavior in the material and the structure was effective in increasing the preciseness of the prediction.

Plastic forming has relevance to the crack initiation and its progress, particularly since the tools are hard and brittle. However, AE signals have not been used to detect crack initiation in tools used in plastic forming to forecast their fracture.

It is desirable to develop a technology that can predict the tool damage and fracture in the plastic forming of metals. Other forming tools and/or press machines could suffer a great deal of damage when a machine operates with a fractured tool. Production has to be stopped quickly when a tool fractures, because the production speed of plastic forming is relatively higher than those of other production methods. Hence, effective real-time monitoring is required.

Punching with various shapes is used for the fabrication of many sheet metal parts. Compressive stress is applied to the punch in the axial direction during the shear process in punching. The punch force is suddenly released when the material fractures, where the magnitude of the impulse depends on the thickness and plastic property of the material. Punches generally have a stepped portion to secure them in the holder. The fatal damage of the punch often arises in the punching of a thick plate, in which the punch separates into two or several pieces, causing serious damage to forming tools and/or press machines. The use 
of high-strength materials has been increasing recently, for example, to reduce the mass and increase the safety of automobile bodies. The load that punches may be subjected to has also been increasing.

Tool fracture with separation in punching may be captured by an AE signal or another method, although the crack initiation or forecasting of fracture has not yet been demonstrated. The crack initiation, growth, opening and closure cause the sudden internal stress redistribution of the forming tool; then, AE as the stress wave is produced. In this study, a circular hole punching test was carried out. The main objective was to capture the occurrence of cracks as a predictive phenomenon of punch fracture and their propagation during punching by installing an $\mathrm{AE}$ sensor into the die set. In addition to $\mathrm{AE}$ waveforms, in order to examine the relationship between the impulsive stress applied to the punch during breakthrough and the punch damage, the axial stress of the punch was simultaneously measured using strain gages attached to the side of the punch.

The punch has a stepped portion with a diameter of $10 \mathrm{~mm}$ for holding it in place, whose material is cold work tool steel. The material of the test plate is carbon steel with a thickness of 5 or $6 \mathrm{~mm}$. The impulsive stress arising immediately after the fracture of the plate was expected to induce damage at the stepped portion under the conditions of this study.

\section{Punching Device and Test Materials}

The die set used for circular hole punching is shown in Fig. 1. When simply punching a circular hole, the simpler structure could be adopted. However, considering the applicability of the research results to the actual production process, we designed the one with the same structure for mass production. The components that require centering are positioned with knock pins. The punching test was carried out by using a hydraulic $300 \mathrm{kN}$ universal testing machine. The punch and die, whose material is SKD11 (HRC60) cold work tool steel, are shown in Fig. 2. The dimensions of the punch with the stepped portion are shown in Fig. 3. The diameter and length are 10 and $100 \mathrm{~mm}$, respectively. Because of the length of the punch, a supporting plate was installed to prevent its deflection, which was removed to clearly show the

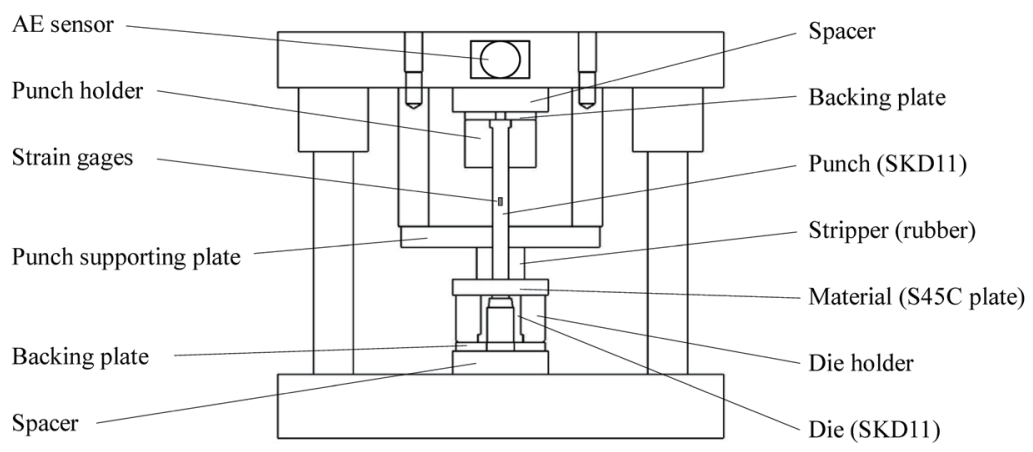

Fig. 1. Punching device with function for measuring axial stress of punch and AE signal. 


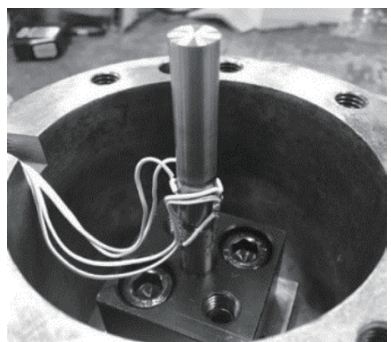

(a)

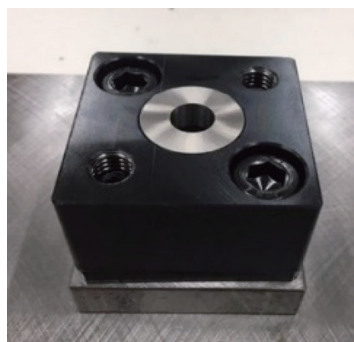

(b)

Fig. 2. Photos of punching tools. (a) Punch with strain gages. (b) Die mounted on holder.

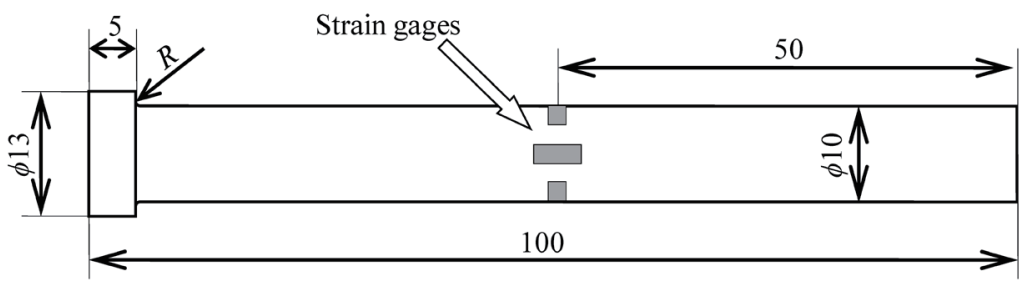

Fig. 3. Dimensions of stepped circular punch and attachment position of strain gages.

punching tools in Fig. 2. The punch and die were set in the dedicated holders. To ensure the alignment between the upper and lower tools, the die set had four guideposts with high rigidity. The clearance between the punch and the die was $0.5 \mathrm{~mm}$, which was 10 or $8.3 \%$ of the plate thickness. These shearing conditions are standard and are commonly adopted in the actual manufacturing process.

The variation in the axial stress of the punch was measured using a full bridge circuit of strain gages (gage length: $2 \mathrm{~mm}$, Kyowa Dengyo, KFG2-120) and a signal conditioner with a wide frequency response (Kyowa Dengyo, CDV-900A). The strain gages were attached $50 \mathrm{~mm}$ from the tip of the punch. The fillet radius $R$ of the punch was measured for each punch using a noncontact three-dimensional measuring device (KEYENCE, VR3100). The AE sensor (NF Corp., AE-900S-WB) was attached to the upper plate of the die set with silicon grease by using a magnetic holder. The AE sensor was able to record the wave in a frequency range from $100 \mathrm{kHz}$ to $1 \mathrm{MHz}$. Considering that the sensor can easily be mounted on the upper or lower plate of the die set at the actual manufacturing site, it was attached to the side of the upper plate. The AE signal is usually weak in the crack behaviors of the forming tool except for its sudden fracture. The output signal of the sensor was amplified by a preamplifier (gain: $40 \mathrm{~dB}$, NF Corp., 9916) to minimize the noise interference and by a discriminator (gain: $10 \mathrm{~dB}$, NF Corp., AE9922).

The test materials were carbon steel S45C plates with a nominal thickness of 5 or $6 \mathrm{~mm}$. Their specifications are listed in Table 1. The ultimate strength and total elongation were similar for both plates. In selecting the material, we first started the experiment with a high- 
Table 1

Thickness and mechanical properties of carbon steel S45C plates.

\begin{tabular}{cccc}
\hline Nominal thickness & Measured thickness & Ultimate tensile strength & Total elongation \\
\hline $5 \mathrm{~mm}$ & $4.96 \mathrm{~mm}$ & $952 \mathrm{MPa}$ & $7.5 \%$ \\
$6 \mathrm{~mm}$ & $5.98 \mathrm{~mm}$ & $1035 \mathrm{MPa}$ & $7.2 \%$ \\
\hline
\end{tabular}

strength steel plate of $2.3 \mathrm{~mm}$ thickness, which is often used for automobile parts. The maximum compressive axial stress of the punch was about $400 \mathrm{MPa}$. Since the punch did not fracture even if it was used for about 30 times in the punching, the plate thickness was increased and the material was also replaced with S45C. A processing condition wherein it would fracture after punching several times was found. ${ }^{(22)}$

\section{Experimental Results and Discussion}

\subsection{Punching test for evaluating performance of device and measurement system}

The first test was carried out on a 6-mm-thick plate. An example of a pair of punched specimens is shown in Fig. 4. The cut face is mostly fractured, but a small part of it is sheared. The material is relatively brittle, which is appropriate for applying a shock load onto the punch. The deformation, which corresponds to the clearance between the tools, is uniform along the circumference; hence, there is no geometrical eccentricity in the pair of punching tools.

Figure 5 shows the time variations of the axial stresses of the punch and AE signal for a 5-mm-thick plate. Compressive stress was taken to be positive for convenience. The recording trigger was set at the rise of the AE signal. The axial stress of the punch increased, reaching a maximum value of $1050 \mathrm{MPa}$, then the material fractured immediately after a decrease in the stress, at which the AE signal appeared, as shown in Fig. 5(a). The oscillatory stress around the triggering event, whose amplitude decreased with time, is shown in Fig. 5(b). The tensile stress reached about $450 \mathrm{MPa}$, which is about half of the maximum compressive stress. However, the stress at material fracture appeared to be about $500 \mathrm{MPa}$, at which the compressive stress started to drop very rapidly. Therefore, the tensile stress was comparable to the compressive stress at the material separation. The punch did not suffer any damage after the punching operation. No AE signal was observed before the force drop. Therefore, if the AE signal is recorded before the fracture of the plate, the AE signal can be regarded as originating from some behavior upon the cracking of the tool.

The continuous punching test was carried out using a 5-mm-thick plate, but no damage occurred even after repeating 20 times. Hence, the plate thickness increased to $6 \mathrm{~mm}$. When the fillet radius $R$ of the punch was $0.42 \mathrm{~mm}$, the punch fractured at the ninth punching. When it was $0.30 \mathrm{~mm}$, the punch fractured at the second punching. The time variation of the axial stress immediately before and after the fracture of the material is shown in Fig. 6 for a 6-mm-thick plate. The amplitude of the oscillatory stress decreased with time. The maximum tensile stress was about $850 \mathrm{MPa}$ as shown Fig. 6(a). The punch fractured after only the second punching, at which the wiring of the strain gages was also damaged, as shown in Fig. 6(b), because the separated portion was suddenly projected when the compression was released. 


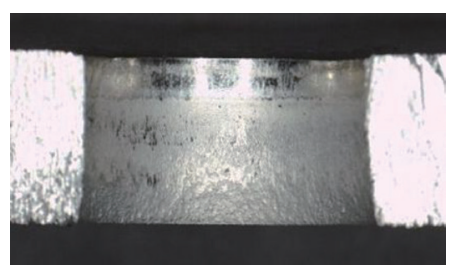

(a)

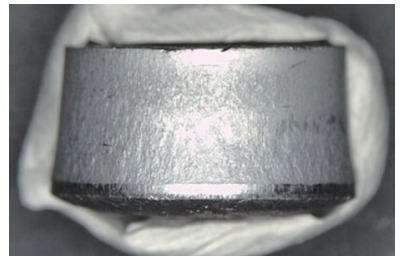

(b)

Fig. 4. Cross sections of (a) hole and (b) scrap (nominal thickness: $6 \mathrm{~mm}$ ).

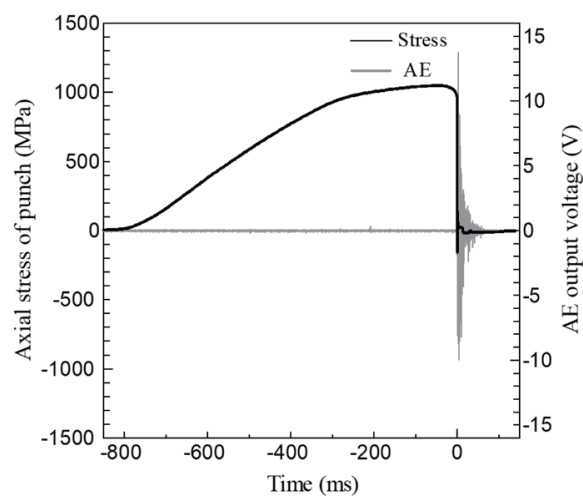

(a)

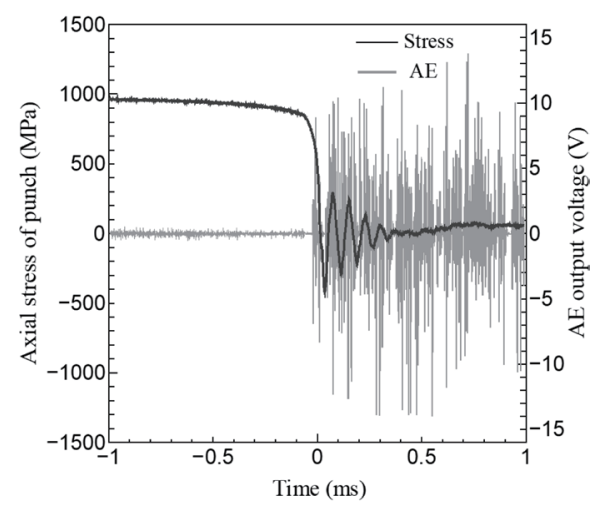

(b)

Fig. 5. Axial stress of punch and AE signal during punching (thickness: $5 \mathrm{~mm}$ ). (a) Variation during punching and (b) variation before and after material fracture.

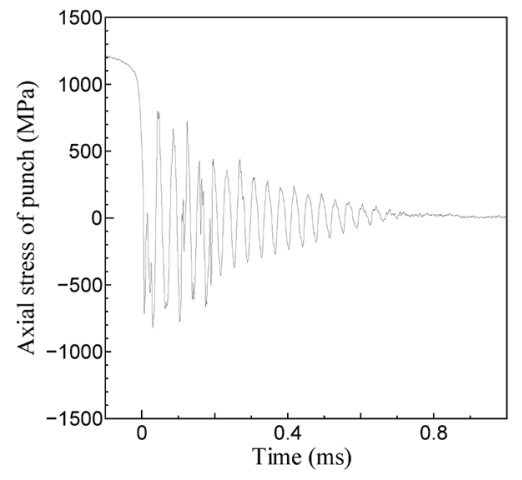

(a)

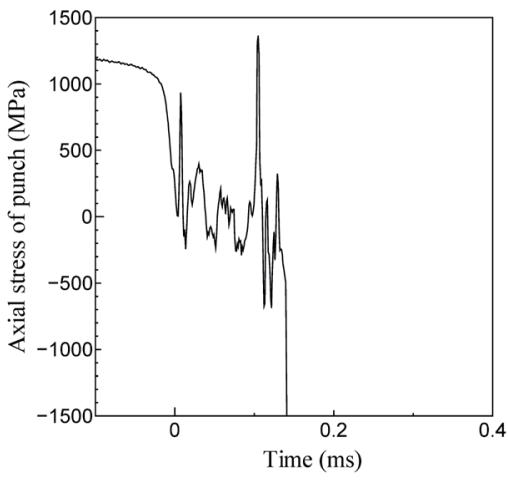

(b)

Fig. 6. Axial stress of punch (thickness: $6 \mathrm{~mm}, R$ : $0.30 \mathrm{~mm}$ ). (a) First punching and (b) second punching.

The fractured punch is shown in Fig. 7. Considering the stress concentration factor of 2.95 at the stepped portion of the punch, ${ }^{(23)}$ the maximum stress was estimated to be $2500 \mathrm{MPa}$. The fracture strength of the material of the punch (SKD11) was estimated to be $2000 \mathrm{MPa} .{ }^{(24)}$ These values are substantially equivalent. 


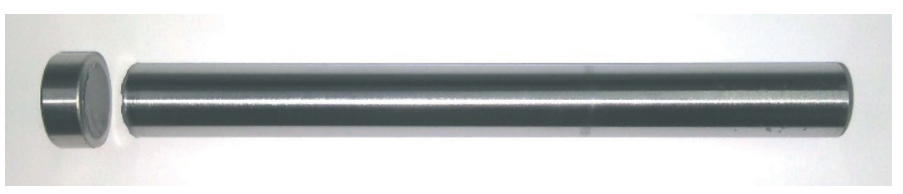

Fig. 7. Fracture of stepped circular punch.

\subsection{Tensile test of punch}

It was worth measuring the fracture force of the punch by conducting a quasi-static tensile test in order to determine the mean allowable stress in the cross section of the punch, because the fracture force or maximum tensile stress depends on the fillet radius. Figure 8 shows the tensile test device installed in a hydraulic universal testing machine. The punch was set in the punch holder to ensure similar conditions to those in the punching experiment. The stepped portion of the punch was inside the punch holder with the straight portion clamped. The AE sensor was attached to a steel block.

Figure 9 shows the experimental results for fillet radii $R$ of 0.30 and $0.16 \mathrm{~mm}$. Their stress concentration factors were 2.95 and 3.71, respectively. Their maximum stresses were 790 and $610 \mathrm{MPa}$, respectively. From these values, the strength of the SKD 11 punch was calculated as 2330 and $2260 \mathrm{MPa}$, respectively, giving an approximate value of $2300 \mathrm{MPa}$. The tensile force was sensed by the hydraulic pressure, whose response was slower than that of the strain gage. However, the maximum stress could be determined from Fig. 9 because the material of the punch showed brittle fracture. From the results shown in Fig. 6, the strength of the punch material was estimated to be $2500 \mathrm{MPa}$ as described above. The punch did not fracture in the first punching, which is attributed to the very short duration of high stress. The AE signal was detected after the fracture of the punch in Fig. 9; no warning AE signal arose before the fracture.

The fractured surface of the punch at the stepped portion is shown in Fig. 10. It exhibited brittle fracture with cracks emanating from the fillet portion. Considering the magnitude of the tensile stress acting on the punch during punching, to obtain an AE signal warning of punch fracture, a repeated punching test using a 5- or 6-mm-thick plate is a reasonable method, because crack formation is expected in the punching of the thicker plate, and gradual crack propagation and/or fracture is expected in the case of the thinner plate.

\subsection{Repetitive punching test}

A steel plate of $5 \mathrm{~mm}$ thickness was used in the first punching, and that of $6 \mathrm{~mm}$ thickness was used in the next operation. Such alternate punching was repeated until fracture occurred. Our aim was to capture AE signals that can warn of fracture. Only the AE signals were recorded in this experiment. If a phenomenon does not cause a large tool vibration such as galling or wear, ${ }^{(6-8)}$ it may be easy to find a problem with the AE and cumulative counts, and so forth. However, when the tool fractures immediately after the processed material fractures, the AE signal caused by the tool fracture is superimposed on that caused by the material fracture. 


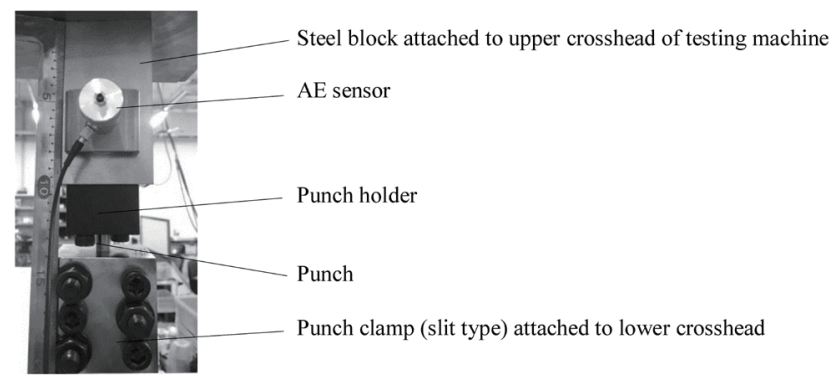

Fig. $8 . \quad$ Tensile test of punch.

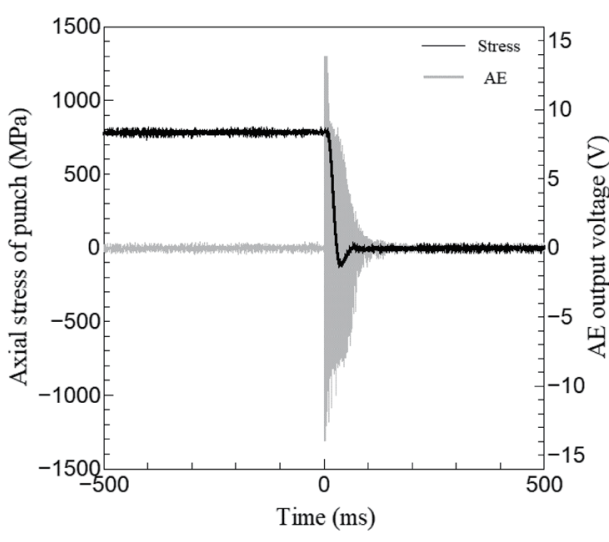

(a)

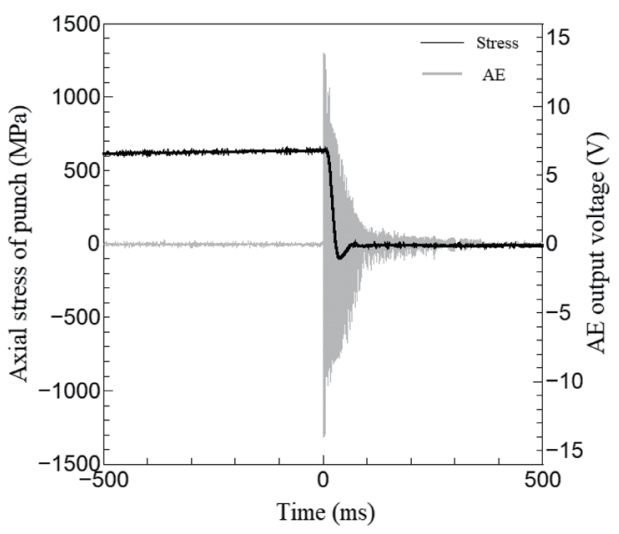

(b)

Fig. 9. Axial stress of punch and AE signal observed in tensile test. (a) $R=0.30 \mathrm{~mm}$ and (b) $R=0.16 \mathrm{~mm}$.

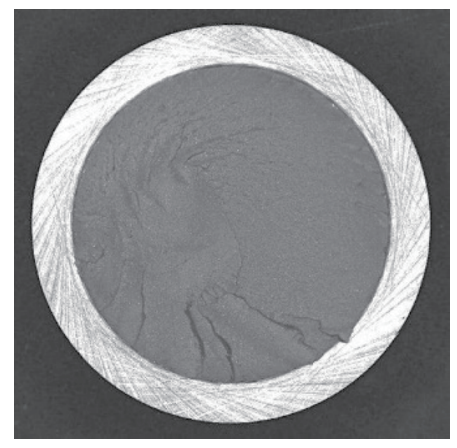

Fig. 10. Fractured surface of stepped portion of punch $(R=0.16 \mathrm{~mm})$.

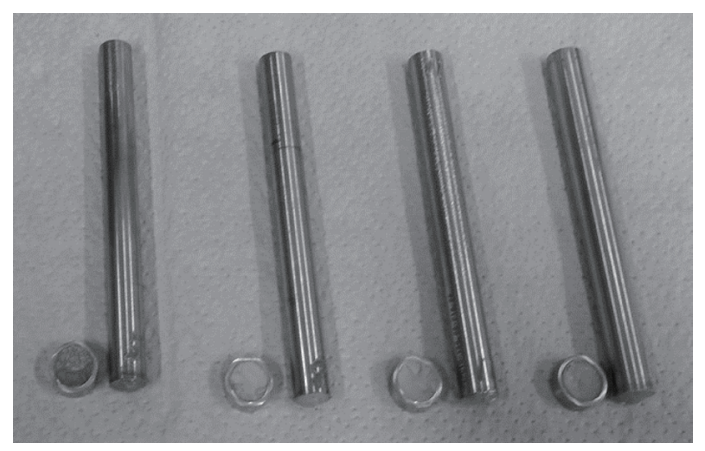

Fig. 11. Fractured punches.

Accordingly, in this study, it may be more appropriate to pay attention to the amplitude rather than the count to capture the features of the entire waveform.

We carried out the repetitive test several times. All punches fractured at the stepped portion as shown in Fig. 11. We encountered two cases in the punch fracture. The first one is a sudden fracture to separate the punch in a single punching, and the second one is that the crack stops during punching. The former case is firstly described. 
Figure 12 shows AE waveforms immediately before and after material separation for the punch fillet radius $R$ of $0.39 \mathrm{~mm}$. Under these experimental conditions, the maximum allowable tensile stress of the punch was calculated to be $852 \mathrm{MPa}$ from the stress concentration factor of 2.70 and the strength of $2300 \mathrm{MPa}$ for the SKD11 punch. The allowable stress is comparable to the maximum tensile stress seen in Fig. 6; hence, fracture was expected to occur before many punching operations. The duration or decay time was longer for the punching with the thicker plate. The punch fractured after the fourth punching of the 6-mm-thick plate. The AE signal was characterized by decay followed by the generation of another waveform as shown in Fig. 12(d). The generation of another waveform may have been due to the impact of the projected punch with the scrap on the backing plate of the die.

In this case, no AE signal warning of fracture was captured, but the AE signal warned of the separation of the punch. Although a punching press machine can be automatically stopped by recognizing this feature of the waveform, the projected part of the punch could cause some damage to other tools.

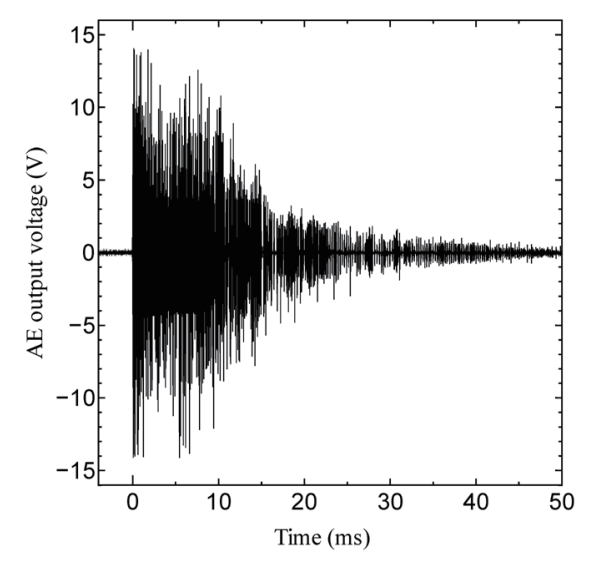

(a)

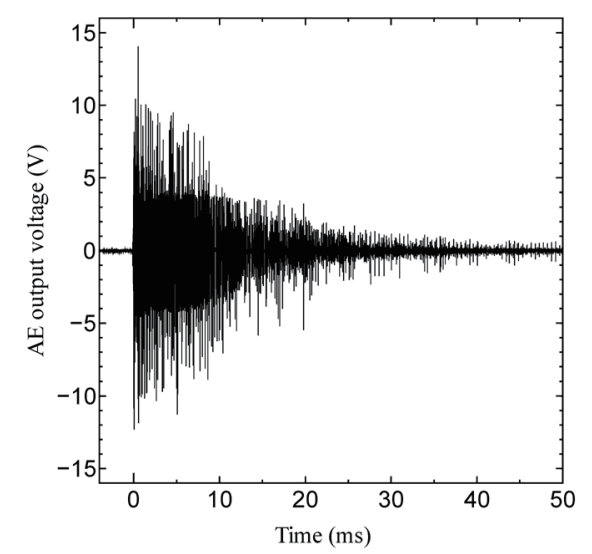

(c)

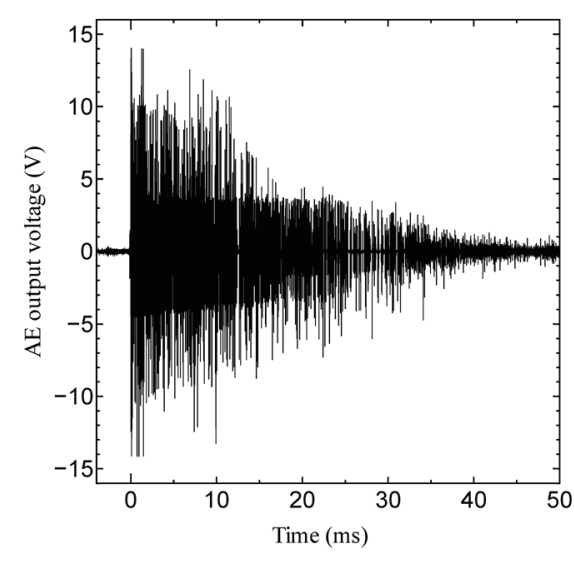

(b)

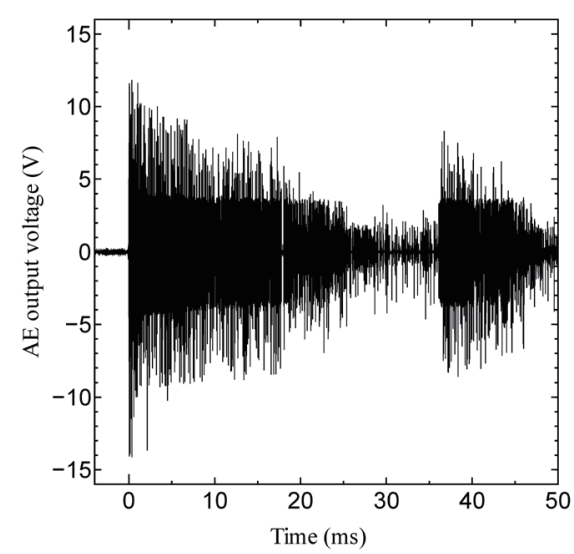

(d)

Fig. 12. AE waveform for punch fillet radius $R$ of $0.39 \mathrm{~mm}$. (a) First punching (thickness: $5 \mathrm{~mm}$ ), (b) second punching $(6 \mathrm{~mm})$, (c) third punching $(5 \mathrm{~mm})$, and (d) fourth punching $(6 \mathrm{~mm})$. 
Figure 13 also shows the AE waveform for the fillet radius $R$ of $0.32 \mathrm{~mm}$. The allowable tensile stress was estimated to be about $800 \mathrm{MPa}$ from the stress concentration factor of 2.89 . The stress level was equivalent to the maximum tensile stress in Fig. 6. Also, under these

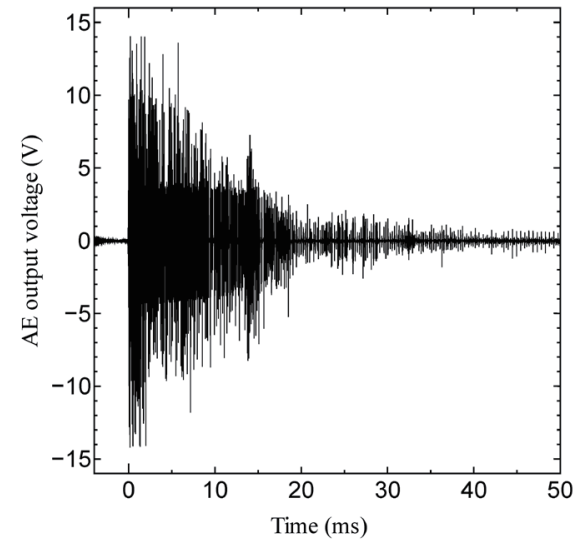

(a)

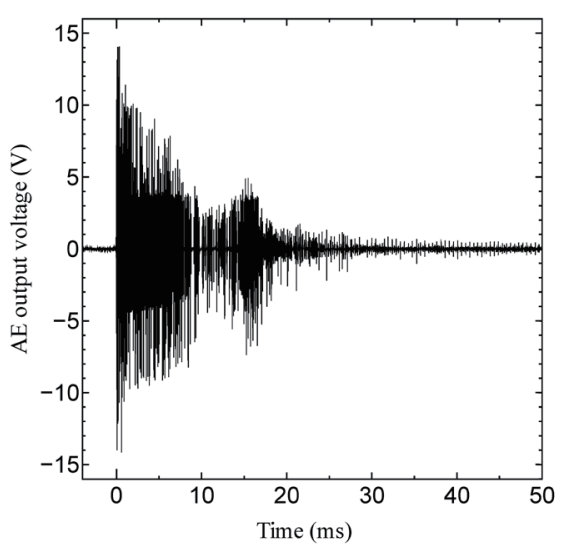

(c)

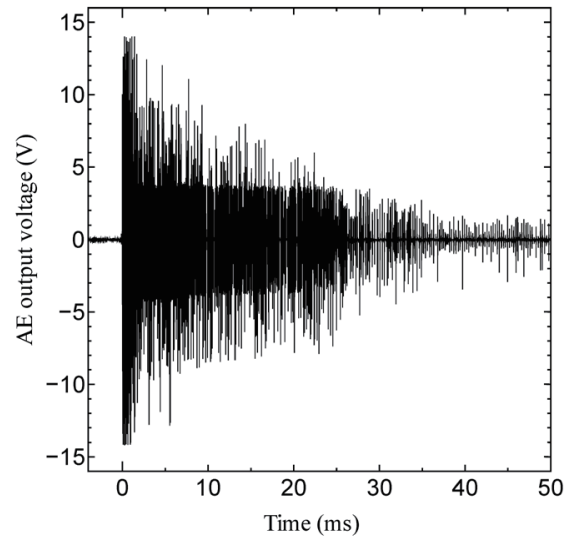

(b)

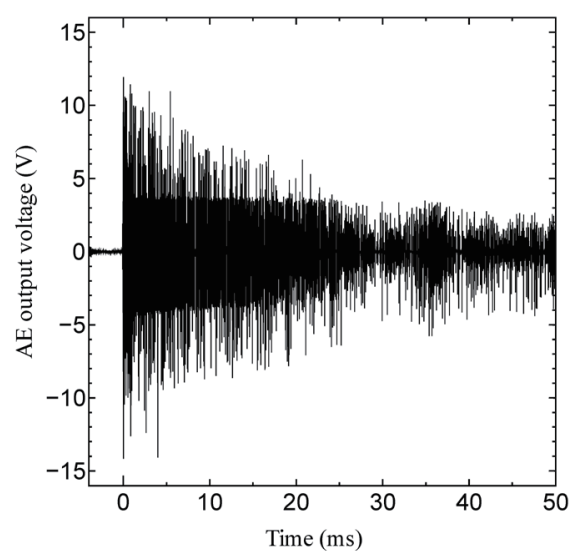

(d)

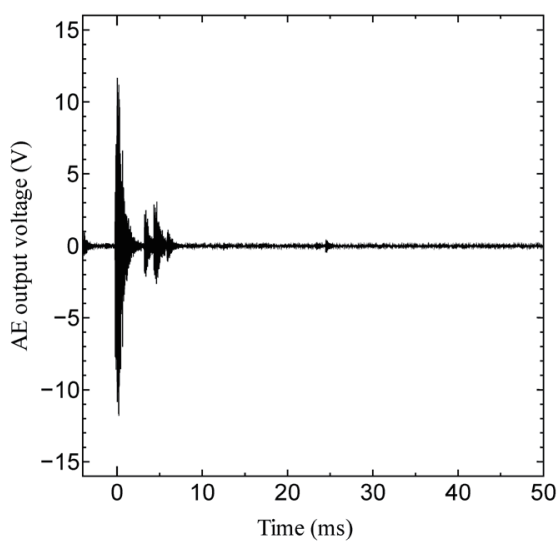

(e)

Fig. 13. AE waveform for punch fillet radius $R$ of $0.32 \mathrm{~mm}$. (a) First punching (thickness: $5 \mathrm{~mm}$ ), (b) second punching $(6 \mathrm{~mm})$, (c) third punching $(5 \mathrm{~mm})$, (d) fourth punching $(6 \mathrm{~mm})$, and (e) fifth punching $(5 \mathrm{~mm})$. 
experimental conditions, fracture was expected to occur without many punching operations. Similarly to the previous case with the fillet radius $R$ of $0.39 \mathrm{~mm}$, the duration of the AE signal was longer for the thicker plate. The decay in the fourth punching is slower than that in the second punching. The punch fractured after the fifth punching. Three spikes in AE waveform were captured before the maximum compressive stress in the fifth punching. The stick-slip behavior of the material and the tool could be understood from the changes in the amplitude of the AE signal. ${ }^{(6)}$ Hence, the first appearance of high amplitude in the fifth punching may correspond to the start of a small slip behavior and crack propagation. The following spikes with smaller amplitudes correspond to the stick-slip behavior between the fractured surfaces. The longer duration of the AE waveform in the fourth punching implies that the stiffness of the punch decreased as a result of crack initiation.

Images of the fractured punches after the experiments corresponding to Figs. 12 and 13 are shown in Fig. 14. The trace of the small crack induced in the fourth punching was observed in the latter experiment but not in the former one. Therefore, the AE signal in the fifth punching was induced by the frictional behavior of the crack and its growth during the compression of the punch. In this experiment, a warning signal for the fracture of the punch was captured. Thus,
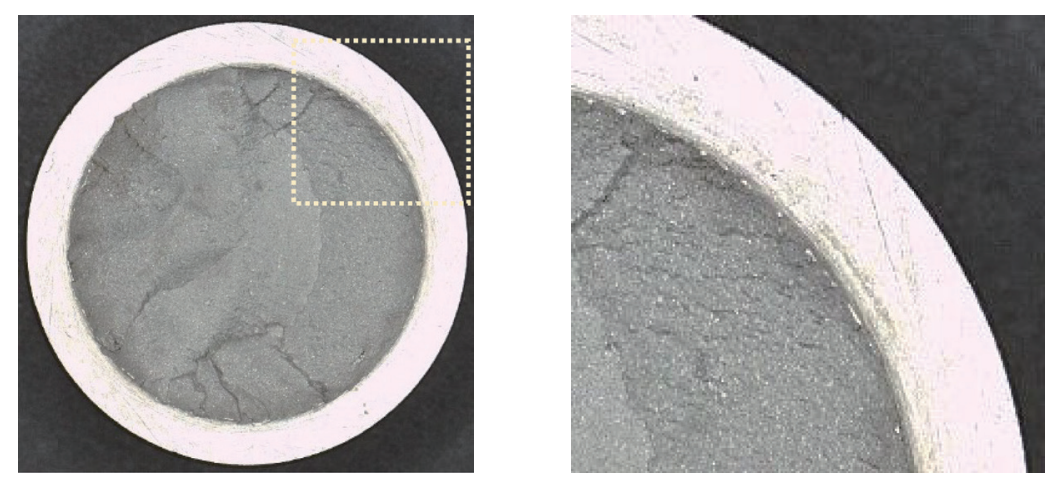

(a)
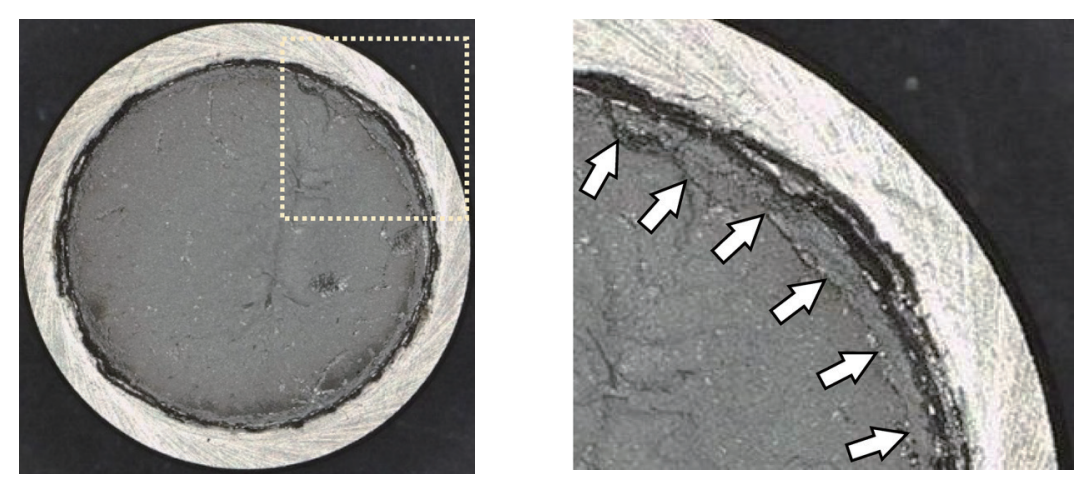

(b)

Fig. 14. Appearance of fracture at stepped portion of punch. (a) (left) General view of fractured surface and (right) magnified view of rectangular area in left photo; $R=0.39 \mathrm{~mm}$. (b) (left) General view of fractured surface and (right) magnified view of trace of small crack at fourth punching; $R=0.32 \mathrm{~mm}$. 
the punching press machine can be automatically stopped with less damage occurring than in the previous case. The maintenance time can thus be decreased because the cracked punch does not cause any damage to other tools.

As pointed out in the fatigue test, ${ }^{(18)}$ the problem is that every measurement is unique for the repeatable application of the AE method, and the materials differ in their acoustic activity and character. For a qualified estimate of the real sources of AE in the material, it is necessary to apply signal processing using suitable mathematical methods and prove detailed frequency analysis. In reference to the studies of crack growth behavior, ${ }^{(20,21)}$ numerical calculation may be necessary to understand more precisely the time variation in the stress and the propagation of $\mathrm{AE}$ waves to eliminate the differences in experimental conditions and to extract the nature of the phenomenon for the damage of the processing tool.

\section{Conclusions}

A circular hole punching test was carried out to capture crack initiation using an AE as a predictive phenomenon of punch fracture and crack propagation. The axial stress in the punch was also measured. The compressive stress was abruptly released at the instant breakthrough during the punching of a thick plate; then, a tensile stress with a similar level of compressive stress to that immediately before the fracture of the plate was observed. The measured stress oscillates and decays with time, as does the AE waveform.

A quasi-static tensile test of the punch revealed that the maximum tensile stress depends on the fillet radius. The stepped portion of the punch fractured. The obtained ultimate tensile strength of the punch material was equivalent to that calculated from the measured maximum tensile stress and stress concentration factor.

A repetitive punching test using 5- and 6-mm-thick plates was performed to detect the formation and propagation of cracks using an AE signal. Three features were found in the AE waveform. The first one was an extra waveform induced by the impact of the fractured punch on the tool of the lower die set. The second one was an AE waveform with a longer decay time, which was induced by the decreased rigidity of the cracked punch. The fracture of the punch was successfully predicted in this case. By capturing this feature in the AE waveform, a punching press machine can be automatically stopped without any damage to the forming tools. The third one was a spiky AE waveform attributed to the frictional behavior and the propagation of the crack. The machine may not be stopped when this feature is detected, because the time interval between the observation of the spiky waveform and the fracture of the plate is very short.

In this study, it was shown that the punch damage or its sign can be grasped by the features of the waveform, and it is industrially useful in that it can be easily introduced to the production site. However, in this study, it was not possible to detect a very small crack and extract its feature. A future research topic may be to capture the contact friction behavior of the processing tool due to elastic deformation as a prestage before microcracks are generated, including signal processing. 


\section{References}

1 S. Hao, S. Ramalingam, and B. E. Klamecki: J. Mater. Process. Technol. 101 (2000) 124. https://doi. org/10.1016/S0924-0136(00)00441-6

2 M. Yanga, K. Manabe, K. Hayashi, M. Miyazaki, and N. Aikawa: J. Mater. Process. Technol. 139 (2003) 368. https://doi.org/10.1016/S0924-0136(03)00533-8

3 I. El-Galy and B. A. Behrens: J. Acoust. Emission 26 (2008) 208.

4 E. M. Gonzalez, I. Picas, D. Casellas, and J. Romeu: Proc. 29th European Conf. Acoustic Emission Testing 2010 (EWGAE 2010)

5 V. V. Nosov and V. G. Lavrin: Russ. J. Nondestr. Test. 48 (2012) 159. https://doi.org/10.1134/ S1061830912030059

6 M. Moghadam, M. H. Suleiman, P. Christiansen, and N. Bay: Procedia Eng. 207 (2017) 1421. https://doi. org/10.1016/j.proeng.2017.10.907

7 M. Moghadam, P. Christiansen, and N. Bay: Procedia Eng. 183 (2017) 59. https://doi.org/10.1016/ j.proeng.2017.04.011

8 B. A. Behrens, S. Hübner, and K. Wölki: J. Manuf. Processes 29 (2017) 281. https://doi.org/10.1016/ j.jmapro.2017.08.002

9 M. Yang: Int. J. Lightweight Mater. Manuf. 1 (2018) 207. https://doi.org/10.1016/j.ijlmm.2018.10.001

10 K. Manabe and T. Oguchi: Sens. Mater. 31 (2019) 3155. https://doi.org/10.18494/SAM.2019.2432

11 M. Yang: Sens. Mater. 31 (2019) 3121. https://doi.org/10.18494/SAM.2019.2399

12 G. Zhang, C. Lia, H. Zhou, and T. Wagner: Procedia Manuf. 26 (2018) 1204. https://doi.org/10.1016/ j.promfg.2018.07.156

13 Y. Segawa, S. Watanabe, Y. Marumo, T. Nonaka, and Y. Sakata: Sens. Mater. 31 (2019) 3163. https://doi. org/10.18494/SAM.2019.2376

14 Y. Murata, T. Nakanishi, N. Hirai, F. Kawanishi, and H. Ibuki: Sens. Mater. 31 (2019) 3099. https://doi. org/10.18494/SAM.2019.2357

15 K. Michihiro, K. Hata, T. Fujiwara, and H. Yoshioka: Mater. Sci. Res. Int. 3 (1997) 106.

16 P. J. S. Cruz, A. D. de Leon, and C. K. Y. Leung: Sens. Mater. 21 (2009) 65. https://doi.org/10.18494/ SAM.2009.521

17 M. Saeedifar, M. N. Saleh, H. M. El-Dessouky, S. T. De Freitas, and D. Zarouchas: Composites, Part A 132 (2020) 105833. https://doi.org/10.1016/j.compositesa.2020.105833

18 P. Mazal, F. Vlasic, and V. Koula: Procedia Eng. 133 (2015) 379. https://doi.org/10.1016/j.proeng.2015.12.667

19 M. Z. Rahman, H. Ohba, T. Yoshioka, and T. Yamamoto: Tribol. Online 3 (2008) 105. https://doi.org/10.2474/ trol.3.105

20 A. Angulo, J. Allwright, C. Mares, T. H. Gan, and S. Soua: Procedia Struct. Integrity 5 (2017) 217. https://doi. org/10.1016/j.prostr.2017.07.119

21 T. Shiraiwa, M. Kawate, F. Briffod, T. Kasuya, and M. Enoki: Mater. Des. 190 (2020) 108573. https://doi. org/10.1016/j.matdes.2020.108573

22 T. Murase, M. Yamashita, and M. Nikawa: Proc. Conf. Tokai Branch of Jpn. Soc. Mechanical Engineers (in Japanese). https://doi.org/10.1299/jsmetokai.2019.68.602

23 N. Noda, Y. Takase, and M. Fujimoto: Trans. Jpn. Soc. Mech. Eng. Ser. C 67 (2001) 49 (in Japanese). https:// doi.org/10.1299/kikaia.67.49

24 K. Fukaura, Y. Yokoyama, D. Yokoi, N. Tsujii, and K. Ono: Metall. Mater. Trans. A 35 (2004) 1289. https:// doi.org/10.1007/s11661-004-0303-5 
